\title{
Redes em subsidiárias de multinacionais: um estudo de caso com análise de redes sociais de inventores e patentes*
}

\author{
Belmiro do Nascimento João**
}

SumÁrio: 1. Introdução; 2. Revisão teórica; 3. Metodologia; 4. Conclusão.

Summary: 1. Introduction; 2. Theoretical review; 3. Methodology; 4. Conclusion.

Palavras-chave: análise de redes sociais; patentes; subsidiárias; internacionalização.

KEY WORDs: social network analysis; patents; subsidiaries; internationalization.

Este artigo mostra a relevância estratégica de uma subsidiária do grupo multinacional Sabó, do setor de autopeças. Foi realizado um estudo de caso com análise de redes sociais e entrevistas com executivos para examinar uma rede de inventores e patentes depositadas entre 1978 e 2008 para esse grupo. Há uma breve revisão da literatura de negócios internacionais e da relevância estratégica de subsidiárias de multinacionais, do papel das redes, complementada pela questão das competências e do conhecimento em subsidiárias. $\mathrm{O}$ artigo parte do mapeamento total da rede (matriz e subsidiárias), de patentes e inventores (atores) para a Sabó, com suas relações investigadas por meio da análise de redes sociais (ARS). A relevância estratégica da subsidiária é enfatizada na estratégia global da empresa. Este artigo analisa as competências essenciais desenvolvidas pela subsidiária, bem como as métricas de rede, destacando a atuação dos principais atores (centrais) e seus papéis na rede como brokers.

\footnotetext{
* Artigo recebido em mar. e aceito em maio 2009.

** Pós-doutorado em administração pela Faculdade de Economia, Administração e Contabilidade da Universidade de São Paulo (FEA/USP) e doutor em comunicação e semiótica pela Pontifícia Universidade Católica de São Paulo (PUC-São Paulo). Professor titular da FEA/PUC-São Paulo. Endereço: Rua Ministro de Godoy, 969, sala 4E-04 - CEP 05015-000, São Paulo, SP, Brasil. Email: bjoao@pucsp.br.
} 


\begin{abstract}
Networks in multinational subsidiaries: a case study analyzing social networks of inventors and patents

This article shows the strategic relevance of a multinational group subsidiary in the auto parts industry. The research included a single case study, social network analysis and interviews with managers in order to examine a network of inventors and patents for the Sabó Group in the period between 1978 and 2008. The article presents a brief review of the literature concerning international business and the strategic relevance of multinational subsidiaries, the role of networks, and the issue of competencies and knowledge in subsidiaries. The study starts by mapping the whole network (headquarters and subsidiaries) - from patents and inventors (actors) towards the Sabó Group -, investigating the relationships through social network analysis (SNA). The strategic relevance of the subsidiary is emphasized by the company's overall strategy. This article examines the core competencies developed by the subsidiary and the network metrics, emphasizing the role of key actors (the most central) and how they act as brokers in the network.
\end{abstract}

\title{
1. Introdução
}

Este artigo apresenta a relevância estratégica de uma subsidiária, por meio da análise de redes sociais, para quantificar os fluxos entre inventores para patentes existentes do Grupo Sabó. Esses fluxos, vinculados à inovação, constituem um dos direcionadores da internacionalização do grupo, em uma indústria global, competitiva, de baixas margens, como é o caso da indústria de autopeças. A questão de partida é: a geração de patentes pode explicar, parcialmente, a relevância estratégica de uma subsidiária em relação à matriz? Para tal resposta foi analisada, para uma multinacional brasileira no setor de autopeças, a rede de patentes constituída tanto para a matriz brasileira quanto para suas subsidiárias, representadas, neste artigo, unicamente, pela subsidiária alemã. Trata-se de um estudo de caso único, com entrevistas semiestruturadas necessárias para a primeira fase da pesquisa (qualitativa) e uma segunda fase (quantitativa) com um método ainda pouco usado em pesquisas de negócios internacionais, a utilização da análise de redes sociais (ARS). Este artigo consiste nesta breve introdução, em uma revisão teórica abrangendo a importância do desenvolvimento de competências pela rede de negócios da empresa, suas subsidiárias e seu fluxo de conhecimento. Ainda na revisão, uma introdução ao papel das redes em negócios internacionais, ou seja, o papel social das relações em uma multinacional. Logo após são apresentadas a metodologia e a empresa. Em seguida, temos uma análise das redes sociais para o Grupo Sabó e, finalmente, as conclusões. 


\section{Revisão teórica}

\section{Competências e fluxos de conhecimento em subsidiárias}

O conceito de competências essenciais passou a ser distinguido como uma característica da organização e é considerado um vínculo entre o conhecimento e a estratégia, como a habilidade de uma organização em implementar ou agir com outras organizações. Prahalad e Hamel (1990) incluem as habilidades técnicas e administrativas que permitem à organização sobreviver, que denominam "competências essenciais". Autores como Furu (2001) afirmam que é possível identificar os direcionadores de desenvolvimento de competências em subsidiárias de P\&D de multinacionais em que, por exemplo, é necessária habilidade para identificar tais competências essenciais de unidades dispersas e como elas influenciam em seu papel corporativo.

Essas competências estão associadas a fluxos de conhecimento que envolvem as operações globais e são um tema importante em estudos de internacionalização de empresas (Kogut e Zander, 1992). Construir colaboração é ferramenta central para atualizar a base de conhecimento organizacional, tanto por meio de parcerias, alianças ou aquisições de outras empresas quanto por processos internos de aquisição de conhecimento. A transferência da capacidade envolvida na codificação do conhecimento se torna real quando o conhecimento tácito referente às inovações se torna mais explícito de maneira a ser mais facilmente comunicado e entendido pelas pessoas (Eisenhardt $\mathrm{e}$ Santos, 2002).

Sveiby (2001) e Sveiby, Linard e Dvorsky (2002) utilizam, a partir da RBV (resource-based view) (Collis e Montgomery, 1995; Carneiro, Cavalcanti e Silva, 1999; Barney e Arikan, 2001), uma epistemologia autopoiética (rede de processos que produz seus próprios componentes) para guiar a formulação da estratégia. Pessoas utilizam sua "capacidade para ação" de modo a criar valor pela transferência e conversão de conhecimento.

Autores como Rainer e Meierkord (2008) alertam que as barreiras à inovação em investimentos baseados em tecnologia necessitam de abordagens criativas por parte das organizações, de seu pessoal, e ainda que há técnicas disponíveis para aumento da colaboração e criatividade e consequente redução da aversão ao risco que podem criar barreiras psicológicas para o pessoal técnico. Entre as abordagens há a gestão da qualidade total - TQM (total quality management), e o Triz (theory of inventive problem solving).

$O$ valor cresce cada vez que uma transferência ou conversão do conhecimento ocorre. Sveiby (2001) e Sveiby, Linard e Dvorsky (2002) definem 
estratégias baseadas no conhecimento para maximizar a criação de valor em uma organização resultante da interação de transferências e conversão do conhecimento entre famílias de ativos intangíveis (estruturas externa e interna e competência individual), de forma que a capacidade para ação das pessoas tanto dentro como fora da organização seja aumentada. Em relação à estrutura interna tem-se a geração de patentes, modelos de negócios, processos, sistemas de informação e outras ferramentas administrativas mais explícitas, que são criadas pelos empregados, geralmente absorvidas, e a organização passa a ter "a posse". Porém, a organização pode possuir legalmente só uma pequena parte da estrutura interna. $\mathrm{O}$ jogo de poder informal, as redes internas e a cultura também podem ser considerados pertencentes à estrutura interna. É útil também incluir a competência dos indivíduos, como o pessoal de apoio, da contabilidade, da tecnologia de informação (TI), de recursos humanos (RH) e de gestão, todos na estrutura interna, desde que não seja possível separar a estrutura interna dos seus criadores. A estrutura interna é assim: em parte dependente e em parte independente dos indivíduos. Até mesmo se os mais valiosos indivíduos deixam uma empresa pelo menos parte da estrutura interna e parte da externa (por exemplo, marcas) permanecerão intactas e podem servir como uma plataforma para um novo ciclo. Ainda segundo Sveiby (2001), a competência individual é representada pela visão do pessoal técnico e profissional e também do pessoal de apoio e administrativo, incluindo pessoal vindo de $\mathrm{P} \& \mathrm{D}$, de processos, vendas e comercialização, em resumo, todos aqueles com contato direto com os clientes ou que influenciam diretamente os clientes da organização. As distinções entre pessoal profissional e técnico e pessoal de apoio e gerencial são feitas porque os seus papéis são diferentes e determinam como eles se relacionam uns com os outros. Essa classificação é útil para a formulação da estratégia e planejamento da ação.

As teorias de negócios internacionais discutem as multinacionais principalmente a partir de uma visão em relação à matriz, mas estudos como os de Bartlett e Ghoshal (1998), feitos a partir da década de 1980, têm enfatizado a importância das subsidiárias para o desenvolvimento da multinacional. Uma das mais importantes contribuições das subsidiárias tem a ver com as atividades inovadoras na transferência ou difusão de conhecimento específico da subsidiária para a matriz bem como outras subsidiárias dentro da multinacional (Bartlett e Ghoshal, 1998; Birkinshaw, 2002; Birkinshaw et al., 1998; Frost et al., 2002; Gupta e Govindarajan, 1991, 2000; Harzing e Noorderhaven, 2006; Tasi, 2001).

Diferentes subsidiárias têm conhecimentos específicos próprios ou de localização (Dunning, 1988, 1994; Molero e Buesa, 1992; Ghoshal e Bartlett, 
1998). Esse conhecimento pode estar relacionado com a experiência em mercados específicos (Birkinshaw e Fry, 1998) ou de tecnologias inovadoras (Birkinshaw et al., 1998) e ambos podem enriquecer o conhecimento básico de uma multinacional.

Além de um conhecimento único no seio das subsidiárias, outros recursos, incluindo uma cultura inovadora da subsidiária ou da sua rede de relacionamentos, também devem ser considerados parte de um recurso base da multinacional. As diferentes fontes de conhecimento dentro delas têm a habilidade de desenvolver novos mercados, no exterior, e de gerar crescimento por meio de novos negócios (Hitt et al., 1997; Markides e Williamson, 1996; Rugman, 1981). Especialmente em atividades inovadoras, as subsidiárias podem fornecer fontes internacionais de conhecimentos tecnológicos, capacidades e vários recursos de mercados, que levam a multinacional a ser mais competitiva que as empresas nacionais (Eriksson et al., 1997; Foss e Pedersen, 2002; Hansen, 2002). Ao se analisar a internacionalização da $P \& D$ e atividades inovadoras, a contribuição para o compartilhamento do conhecimento da subsidiária não pode ser ignorada.

\section{O conceito de redes em multinacionais}

Para um melhor entendimento do papel das redes em multinacionais serão apresentados, nesta seção, vários conceitos, entre eles: redes de negócios, redes diferenciadas e fluxos e papéis.

No entanto, neste artigo, o foco não é explicar unicamente a forma como as características específicas da rede trazem benefícios para uma subsidiária, mas sim analisar o modo com que elas difundem o conhecimento dentro da multinacional depois de estabelecer redes diversificadas de relacionamentos em locais específicos (De Pablos, 2004; Iwasa e Odagiri, 2004; Jensen e Szulanski, 2004; Lindqvist et al., 2000; Malik, 2004).

Devemos, portanto, tomar as multinacionais como uma ampla rede global (Birkinshaw, 2002; Lam, 2003; Powell, 1990), dentro da qual cada subsidiária (ou nó) estabelece uma rede específica em sua área local. Os vários recursos de redes dentro das multinacionais são as fontes para explorar o conhecimento globalmente.

O termo "redes de negócios" foi inicialmente utilizado pela escola de Uppsala, Suécia, nas décadas de 1970 e 1980 e muitas ideias sobre poder e influência emergiram desse centro de pesquisa. Forsgren, Holm e Johanson (2005) apresentam o conceito de "embedded multinational", em que os auto- 
res mostram como as redes internas de uma multinacional interagem com as redes externas que cada subsidiária tem em seu mercado local. Uma característica especial da "embedded multinational" é o papel dual das subsidiárias individualmente, dependendo do contexto da sua rede de negócios e do contexto corporativo a que cada uma pertence simultaneamente. Essa característica, por sua vez, tem um impacto profundo na multinacional.

O conceito de "embeddedness" surgiu inicialmente com Polyani (1957) e foi desenvolvido posteriormente por Granovetter (1985), refletindo a visão de que as trocas econômicas são "embedded" nas trocas sociais e culturais. A ideia básica em torno da noção de "embeddedness" é a de que as estruturas sociais jogam um papel significativo no comportamento da economia.

Há diversos trabalhos de redes na literatura de negócios. Cross, Nohria e Parker (2002) apresentam um estudo sobre a importância das redes informais e uma análise de como aplicar a análise de redes sociais. Cross e colaboradores (2001) debatem a criação de conhecimento e seu compartilhamento em redes sociais. Do mesmo modo Cross, Baker e Parker (2003) questionam sobre a criação de "energia" nas organizações por meio de redes sociais.

Ainda na literatura de negócios internacionais, Money (1998) discute a questão das negociações e redes sociais incluindo a questão da cultura nacional e utiliza software de análise de redes para sua análise que também é usado por Coviello (2006) para explicar a dinâmica de redes em novos investimentos internacionais. Chua, Morris e Ingram (2008) utilizam redes sociais para a discussão de redes de gerentes norte-americanos e chineses. Trabalhos recentes sobre análise de redes sociais em negócios internacionais indicam um campo fértil para pesquisas, como os estudos de Ho e Chiu (2008) e Han, Bewaji e Kothari (2008) sobre capital social e o desempenho de subsidiárias, e o trabalho de Ho, Chiu e Yang (2008) sobre medidas de centralidade em joint ventures internacionais.

O conceito de redes tem sido frequentemente utilizado em estudos de negócios para explicar como as empresas podem utilizar os recursos específicos de rede para alcançar metas estratégicas (Burt, 1992, 1997; Camagni e Capello, 2000; Holm et al., 1996; Jones et al., 1997; Oliver e Ebers, 1998).

Ainda segundo a teoria de redes sociais, quando um ator, que pode ser um indivíduo ou uma empresa, tem ligações com outros nós que possuem conhecimento superior no âmbito da rede, ele pode adquirir conhecimento a partir das ligações de rede. Estudos focam o uso de características estruturais da rede como, por exemplo, a centralidade, relações não redundantes (structural hole), ou laços fortes e fracos para medir o acesso aos recursos de 
rede específicos por um ator (Burt, 1992, 1997; Gupta e Govindarajan, 2000; Hansen, 1999; Madhavan et al., 1998).

Redes de conhecimentos diversificadas, incluindo as fontes internas e externas, motivam as empresas a inovar e apresentar um desempenho superior (Malik, 2004; Manolopoulos et al., 2005). Doz, Santos e Williamson (2001), no que denominam empresa "transnacional", ressaltam a importância das fontes internacionais para as empresas acumularem capacidades específicas, o que é compartilhado por Sadowski e colaboradores (2003) na análise do caso da Nokia, não somente fontes internas, mas também externas, como fornecedores, manufatura, parceiros em joint ventures internacionais (Ho, Chiu e Yang, 2008) são importantes atores dentro de redes inovadoras. O estudo de Birkinshaw e Fry (1998) enfatiza as redes internas, uma subsidiária pode esforçar-se por otimizar a rede de comunicação interna e estabelecer um papel de coordenação única dentro da multinacional. Já Pantzalis (2001), para as fontes externas, salienta que uma subsidiária cria valor e mais recursos para si mesma por desenvolver a sua rede local de relacionamentos. Isso mostra que as empresas reforçam sua base de conhecimento por meio do acesso a fontes externas de conhecimento (Fey e Birkinshaw, 2005), como por exemplo, por meio de muitas redes externas de comunicações e de relacionamentos, redes com universidades locais que fornecem oportunidades mais cooperativas para atividades inovadoras para toda a multinacional (Gupta e Govindarajan, 2000; Nobel e Birkinshaw, 1998).

Buckley e Ghauri (2004) têm argumentado que estudos em subsidiárias e negócios internacionais devem considerar a rede de conhecimentos globalmente, com subsidiárias analisadas como nós valiosos dentro da multinacional. Em outras palavras, a rede de relacionamentos, incluindo recursos de rede internos e externos, são os mecanismos interativos e recursos únicos que facilitam interações do conhecimento dentro das organizações.

As multinacionais são como uma rede, incluindo os fluxos de capitais, de produtos e de conhecimento. Para as atividades inovadoras nas diferentes subsidiárias, a interação do conhecimento desempenha um papel relativamente importante (Ensign et al., 2000; Gupta e Govindarajan, 1991). No entanto, como para a maioria dos estudos em negócios internacionais, discussões sobre fluxos de conhecimento são vistas a partir do país sede com foco no conhecimento, na sua gestão, coordenação e controle estratégico.

Os estudos centrados na matriz falham em reconhecer o papel das subsidiárias, que é a unidade localizada nas proximidades das fontes de conhecimento externo. Nohria e Ghoshal (1997) descrevem a "rede diferenciada" como disponibilizando um contexto de experimentação por meio da recombi- 
nação de conhecimento dispersa pelo mundo. Os autores constroem a noção fundamental de que as unidades de uma multinacional podem ser organizadas como uma rede diferenciada, de modo a aperfeiçoar o uso de recursos, encorajar a troca e o desenvolvimento de conhecimento e incrementar a inovação. Os autores ainda mostram que todo o desempenho da subsidiária é positivamente correlacionado com o alto grau de diferenciação interna e de valores compartilhados e incorporados pela subsidiária e examinam a importância dos mecanismos de interação.

As subsidiárias, como parte das multinacionais, têm mais oportunidades de acesso a diferentes recursos ou de absorção de diferentes conhecimentos em países distintos. Essas características inovadoras dentro das subsidiárias incluem a atitude, o comportamento e capacidades renovadoras, que representam a forma como poderiam contribuir para todas as atividades da multinacional. As subsidiárias, com o objetivo de alcançar uma posição crítica dentro das multinacionais, podem ter vantagem por seus conhecimentos e recursos específicos para atingir tal posição. Além disso, quando uma posição de importância estratégica é estabelecida, as subsidiárias podem obter mais apoio da matriz e desenvolver mais recursos locais para o compartilhamento dentro da multinacional. Capacidade e características inovadoras tornam as subsidiárias mais ativas no compartilhamento de conhecimentos. No entanto, esse compartilhamento de conhecimentos entre as unidades implica que as subsidiárias já não possuam recursos exclusivos, diferentes das outras unidades. Quando as subsidiárias estabelecem capacidades específicas e conhecimentos acumulados únicos a partir de sua região, elas podem desejar manter um certo grau de autonomia em relação às suas estratégias locais (Bartlett e Ghoshal, 1998).

Redes de relacionamentos são recursos específicos que as empresas estabelecem (Burt, 1992, 1997; Nahapiet e Ghoshal, 1998). Redes internas não se concentram em trazer novos conhecimentos de fora, mas sim de criar o ambiente e a cultura interativa entre as unidades. Por meio de uma atmosfera interativa e cultural, dentro das multinacionais, a rede de relacionamentos internos incentiva os fluxos de conhecimento de forma eficiente e motiva as subsidiárias a compartilharem mais entre as unidades internas (Birkinshaw e Fry, 1998; Stabell e Fjeldstad, 1998).

Estudos de redes apontam que o enraizamento relacional (embeddedness), ou seja, a rede de relacionamentos, pode motivar a transferência de conhecimentos e de interações entre as diferentes unidades (Kostova, 1999). Redes internas com matriz ou de outras subsidiárias acumulam confiança social entre o pessoal interno. $O$ processo de socialização incentiva as subsidiárias a ampliarem o compartilhamento dos conhecimentos que adquiriram (Nahapiet 
e Ghoshal, 1998; Oliver e Ebers, 1998). As conexões sociais, via rede interna de relacionamentos, auxiliam todas as unidades dentro das multinacionais a acessarem um conhecimento único, específico da localização ou específico de cada subsidiária, a partir de outras subsidiárias (Bartlett e Ghoshal, 1998).

Birkinshaw e Fry (1998) propõem que as subsidiárias podem desempenhar o papel para otimização da rede interna, o que significa que as subsidiárias procuram ineficiências e eliminam atividades dentro da rede multinacional. Diferentes centros de P\&D, nas subsidiárias das multinacionais, estão localizados em lugares diferentes e têm papéis específicos. Isso proporciona coordenação das diferentes atividades funcionais dentro da multinacional e visa cumprir as metas da empresa (Birkinshaw, 2002). Assim, subsidiárias específicas desempenham papéis de corretagem (brokerage), como coordenador ou gatekeeper, no âmbito das redes internas e melhoram as comunicações nesse ambiente. Redes internas facilitam as relações entre os fluxos de conhecimento e fortalecem a capacidade de inovação da multinacional. O papel de facilitar as interações do conhecimento também pode dar a uma subsidiária uma posição crítica em matéria de inovação para o conjunto da multinacional.

De acordo com Rugman e Verbeke (2001), as estratégias da matriz agem como condutoras para a aprendizagem, nas subsidiárias, em diferentes conhecimentos provenientes de outras unidades dentro das multinacionais, melhorando a capacidade inovadora das subsidiárias. A forte relação entre a capacidade inovadora das subsidiárias e os recursos da matriz é demonstrada na citação de dados de patentes como a apresentada por Frost (2001). Isso encoraja a análise das características inovadoras da subsidiária que pode ser a mediadora para fortalecer o impacto das estratégias da matriz (incluindo estratégias centralizadas e mecanismos de intercâmbio de pessoas) no comportamento de compartilhamento de conhecimento da subsidiária.

\section{Metodologia}

$\mathrm{O}$ artigo seguiu todas as fases de desenvolvimento de uma pesquisa em administração, de acordo com Cooper e Schindler (2003), incluindo as fases de planejamento, coleta de dados, análise, interpretação e a elaboração de relatório final. Trata-se de um estudo de caso único que, na visão de Eisenhardt (1989), é uma estratégia de pesquisa pela qual se compreende a dinâmica de um fenômeno a partir de sua singularidade que pode ser apreendida pela observação de um caso único. Para Stake (2005) reflete a escolha do que deve ser estudado e que, independente dos métodos, é o caso que interessa tanto 
que técnicas quantitativas e qualitativas podem ser mescladas no intuito de compreender o caso. Assim, o interesse está no caso, mesmo que ele seja um instrumento de revelação de padrões conhecidos ou mera exemplificação de relações teóricas. Para Yin (1986) o estudo de caso único pode ser classificado como crítico, revelador ou em profundidade. Para o estudo de caso revelador, tem-se aquele que exemplifica uma condição apenas teoricamente discutida, porém ainda não observada empiricamente.

Os dados utilizados no trabalho foram obtidos de fontes secundárias e primárias. As principais fontes secundárias foram publicações internas do Grupo Sabó (Sabó Indústria e Comércio de Autopeças Ltda. e Kaco GmbH Co.) e de alguns de seus principais players, como a Freudenberg alemã, estudos setoriais e artigos de periódicos na área de administração e journals. Para o estudo de caso, foram utilizadas como fonte primária entrevistas semiestruturadas, feitas com executivo de marketing e com gerente de engenharia de desenvolvimento de produtos da Sabó. Posteriormente foi realizada a coleta e análise dos dados de patentes, obtidos diretamente da base de dados DWPI (Derwent world patents index, 2008), que tem como provedora a Thomson Reuters. Cada patente, na base de dados, é descrita por um conjunto de atributos tais como: número da patente, título, nome do inventor, empresa solicitante, resumo da patente e datas de solicitação e de concessão.

Para a análise do Grupo Sabó foi coletada a totalidade de suas patentes na base de dados da DWPI (2008) distribuídas entre a Sabó Indústria e Comércio de Autopeças Ltda. e a Kaco $\mathrm{GmbH}$ Co., o que cobre o período entre 1978 e 2008, correspondendo a 136 patentes e 65 inventores. Essa população (full sample) corresponde, em relação ao seu escopo, a uma rede do tipo "redes totais" (whole networks), pois a unidade de análise é uma empresa que foi submetida à análise de redes sociais (Hanneman e Riddle, 2001; Borgatti et al., 2002), sucessivamente, por meio da exportação de dados brutos do DWPI para o Excel (patentes, inventores e seus atributos) e deste para o Ucinet 6 para Windows (versão 6.202) (preparação e análise das matrizes) e para o visualizador de redes NetDraw 2.081 (análise dos grafos). Um maior detalhamento dos procedimentos é apresentado na seção da análise de redes sociais para o Grupo Sabó.

\section{O caso Sabó}

O Grupo Sabó fabrica e comercializa produtos para vedações dinâmicas, ou seja, retentores, vedações estáticas (juntas) e mangueiras, que constituem três 
distintas unidades de negócios cujo mercado abrange desde montadoras de veículos, no mercado doméstico e no exterior, empresas de reposição de autopeças, até fabricantes de implementos agrícolas e de eletrodomésticos. É hoje a terceira maior fornecedora de sistemas de vedação para a indústria automobilística mundial.

Fundada na cidade de São Paulo, em 1942, a empresa começou produzindo retentores e, com o passar do tempo, incorporou outras linhas de produtos como consequência da aquisição de indústrias de juntas e de mangueiras. Na década de 1990, a Sabó comprou duas fábricas de retentores na Argentina (Todaro e Wol) e cinco na Europa (Kaco). Com unidades de produção no Brasil (São Paulo e Mogi Mirim), Argentina (Buenos Aires), Alemanha (Heilbronn, Kirchardt e Talheim), Áustria (St. Michael i. Lg.), Hungria (Enese), Estados Unidos (Carolina do Norte), China (Wuxi), escritórios em diversos outros países e dois centros de pesquisa (Brasil e Alemanha). As equipes envolvidas com o desenvolvimento tecnológico, objeto deste artigo, estão localizadas no Brasil e na Alemanha. A Alemanha é considerada centro de excelência em plásticos e elastômeros.

Em relação às plantas industriais, as operações nas Américas trabalham com o nome Sabó, já as operações europeias e a chinesa com a denominação Kaco.

O grupo conta com cerca de 3.500 funcionários em todo o mundo, dos quais 2.200 no Brasil e possui um faturamento de mais de US\$ 300 milhões/ ano e investe entre $5 \%$ e $7 \%$ do faturamento em P\&D, o que ajudou a gerar as 136 patentes apontadas na pesquisa. Cerca de $30 \%$ das vendas a cada ano provêm de novos projetos com clientes.

Para a manutenção de suas competências, atua com um pequeno conjunto de tecnologias e produtos básicos, agregando valor. Ao concentrar sua atuação em retentores, o Grupo Sabó ganha escala e a utiliza estrategicamente.

Tanto a Sabó como a Kaco se complementam em termos de tecnologia. Desse modo, acabam beneficiadas pela união. Os engenheiros da Kaco contam com o auxílio de dezenas de profissionais de desenvolvimento da Sabó no Brasil para criar produtos e materiais, e vice-versa.

Com a aquisição da Kaco, o grupo obteve algo que é importante como fluxo de conhecimento (Bresman, Birkinshaw e Nobel, 1999), ou seja, a proximidade com os centros de decisão das montadoras na área de desenvolvimento de produtos. Fato esse conhecido como client following, pois os engenheiros do Grupo Sabó estão próximos dos seus clientes.

Exemplos de desenvolvimento conjunto com montadoras são os novos sistemas de vedação que, após serem desenvolvidos junto à matriz da montadora, são replicados para outras plantas espalhadas pelo mundo, o que auxilia em sua estratégia global. 
A cultura alemã voltada à inovação tende a ser replicada no Brasil, mas há certos conceitos de gestão que a Sabó tem dificuldades em introduzir na Europa, por causa das diferenças culturais, como o trabalho por células de gestão, adotado na matriz brasileira desde 1996. Os funcionários formam células (equipes multifuncionais), e cada uma delas é dedicada a um grupo de 10 a 30 clientes. Na Sabó existem dezenas dessas células, que contam com funcionários de diferentes áreas incluindo: comercial, engenharia de produto, qualidade, processo, materiais e logística. Em seus escritórios, cada membro trabalha em equipe. Esse trabalho por células também traz mais agilidade ao atendimento. Antes, o tempo necessário entre o pedido de um cliente e a entrega de um protótipo era de cerca de quatro meses, e foi reduzido para um mês. Se o cliente tem um problema, são os membros da célula que cuidam de tudo. Essa configuração auxilia os fluxos de conhecimento por agilizar a comunicação entre os diversos departamentos. Assim, a solução de projetos junto aos clientes fica otimizada.

Em relação aos mercados maduros, a agilidade no atendimento, além da qualidade, é condição vital para que a empresa seja bem-sucedida nesse mercado, pois seus principais concorrentes são todos maiores (por exemplo, a alemã Freudenberg). Por mais que a Sabó aumente sua produtividade em razão do crescimento de automação das linhas, os ganhos de escala que os concorrentes têm são significativos. Desse modo, para competir, a Sabó tem que ser ágil no atendimento e ter produtos confiáveis. Um dos parâmetros de medição é traduzido pelos prêmios de fornecedores mundiais de seus parceiros.

Há diretorias específicas de tecnologia tanto no Brasil como na Alemanha. A estratégia voltada para o futuro é, desse modo, compartilhada no Grupo Sabó e há a utilização intensiva de videoconferência entre a matriz e as subsidiárias.

Um exemplo de pesquisa que resultará em produtos (retentores) a serem utilizados em aparelhos de ar condicionado automotivos europeus a partir de 2011, devido à proibição de aparelhos que utilizem líquidos refrigerantes halogenados denominados comercialmente freon $\AA$, como o CFC-12, e a utilização de fluido refrigerante, como o $\mathrm{CO}_{2}$, para a próxima geração de aparelhos de ar condicionado automotivo. O Grupo Sabó terá, desse modo, um produto inovador para as montadoras europeias.

Outro aspecto forte da pesquisa na Alemanha é a participação conjunta com universidades e a própria Kaco deve abrir seu centro de inovação tecnológica na cidade de Kirchardt, onde há uma grande proximidade das matrizes de grandes montadoras globais devido às solicitações de clientes. Já a estratégia de client following, existente desde 1992, pode ser considerada uma forma de reduzir a distância psíquica, ao menos quando este conceito é interpretado a partir das diferenças entre empresas e não das diferenças entre países, como o conceito foi originalmente proposto pela escola de Uppsala. 
Outra estratégia tecnológica, mais antiga, foi a decisão, em 1962, da empresa investir em laboratório próprio de P\&D. O foco em tecnologia sempre foi um dos principais alicerces da cultura organizacional da Sabó e está alinhada à forte cultura tecnológica das empresas alemãs.

\section{Figura 1}

Atuação global do Grupo Sabó

(plantas, centros de distribuição e escritórios)

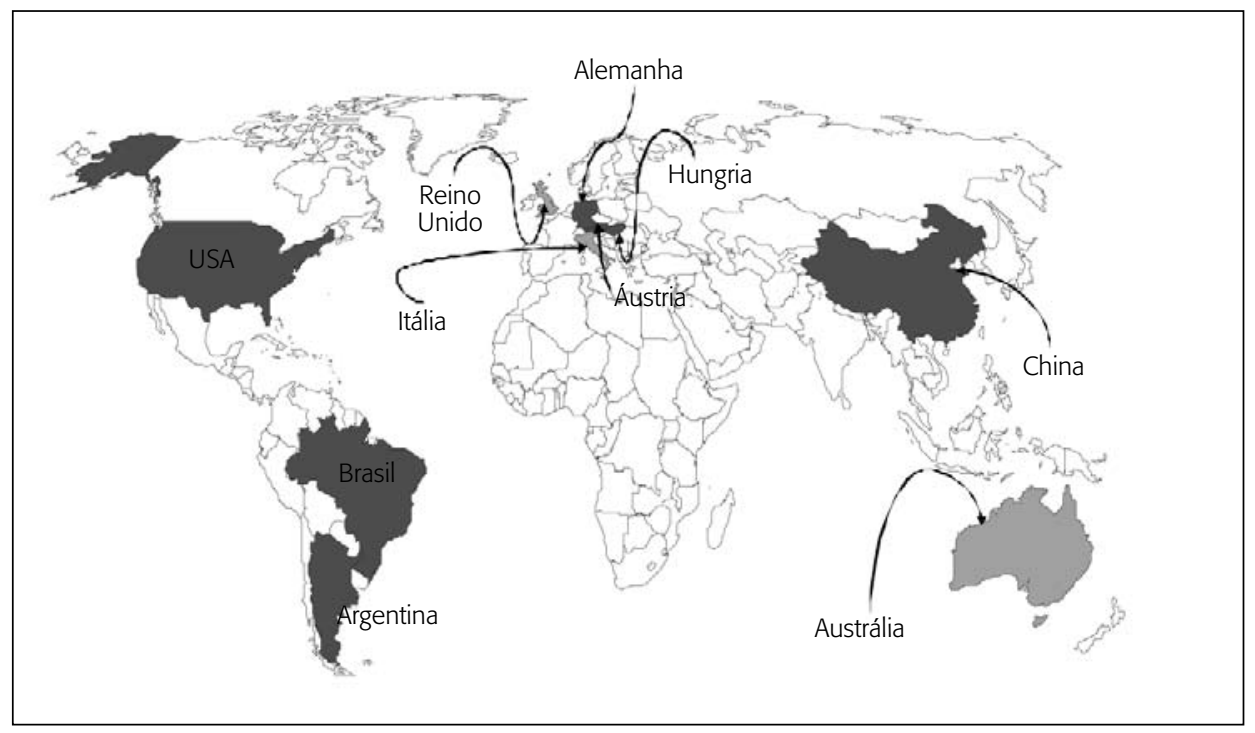

Fonte: Dados da pesquisa.

A figura 1 apresenta a atuação global do Grupo Sabó, suas plantas e escritórios técnico-comerciais. Um grande desafio é fazer com que as operações no Brasil e na Europa trabalhem de forma mais unificada.

\section{Análise de redes sociais para o Grupo Sabó}

O método de análise de redes consiste em um conjunto finito de atores e as relações definidas entre eles (Wasserman e Faust, 1994), método que permite analisar e comparar diferentes relacionamentos e fluxos entre os membros da rede (produção, tecnologia, finanças, trabalho, ativos, patentes), fluxos de conhecimento (tecnologia, inovação, informação), fluxos de capital humano (trabalhadores), fluxos de decisões, fluxos de propriedade e a análise de uma 
rede de inovação. Neste artigo, a análise de redes sociais é utilizada como uma ferramenta analítica dos padrões de interações entre inventores (atores sociais) que formam estruturas que organizam o comportamento desses atores. O foco é nas relações sociais entre os atores e não em seus atributos. Os dados de patentes incluem a matriz e a subsidiária alemã do Grupo Sabó, apresentando dados estatísticos e grafos de rede (sociogramas) com nodos e arestas.

Foi feito um mapeamento das relações e suas medidas estatísticas que sejam representativas do grau de relações, permitindo responder a questões tais como: quais são os atores centrais; como estão distribuídas as inovações (via patentes) pela empresa; e qual o fluxo de informações relacionadas com patentes para o Grupo Sabó.

O primeiro procedimento foi a extração dos dados brutos da DWPI com a totalidade dos atores (inventores). Esses dados foram normalizados evitando-se duplicidade. Para construção da rede foram criadas planilhas com matrizes usando o software Ucinet 6.0, uma ferramenta de análise de rede social desenvolvida por Borgatti e colaboradores (2002). Conforme recomendado por Hanneman e Riddle (2001), cada matriz foi composta por todos os atores $(n=65$, numeradas de i02 a i68, em ordem alfabética, com i41 e i65 ausentes devido a duplicidades na base de dados) e por todas as patentes ( $\mathrm{n}=136$, numeradas de $\mathrm{p} 001$ a $\mathrm{p} 136$, da mais antiga para a mais recente) para a análise, com laços codificados como ausente (0) ou presente (1), ou seja, dados binários ou calculados simplesmente a partir de uma relação binomial - existência ou ausência de vínculos. A matriz inicial foi criada como do tipo "2-mode" (Borgatti e Everett, 1997), que relaciona atores versus eventos, e posteriormente foi convertida em matrizes quadradas e simétricas, com o uso do software Ucinet 6.0 e analisado graficamente pelo software Netdraw 2.081.

A pesquisa demonstra que a rede de patentes e inventores para o Grupo Sabó apresenta a seguinte configuração: as 136 patentes analisadas compreendem o período entre 1978 e 2008. Destas, $44(32,4 \%)$ têm origem na matriz brasileira e $92(67,6 \%)$ na subsidiária alemã. Entre 1978 e 1991 foram depositadas pela Kaco 45 patentes (numeradas de P001 a P045 no estudo), ainda sem o controle da Sabó, que correspondem a 48,9\% de todas as patentes da subsidiária durante o período da análise. As primeiras quatro patentes brasileiras do estudo, de 1993, ano da aquisição da subsidiária alemã pela Sabó, correspondem às patentes P046, P048, P049 e P050, e correspondem ao grupo de fundadores da Sabó (inventores I51 a I53). No período compreendido entre 1993 e 2002 há um crescimento no número de patentes pela matriz brasileira em relação à subsidiária alemã. A partir de 2003, no entanto, as patentes da subsidiária alemã ultrapassam as da matriz brasileira até o final do período de análise como apresentado na figura 2 . 
Figura 2

Patentes para o Grupo Sabó (1978-2008)

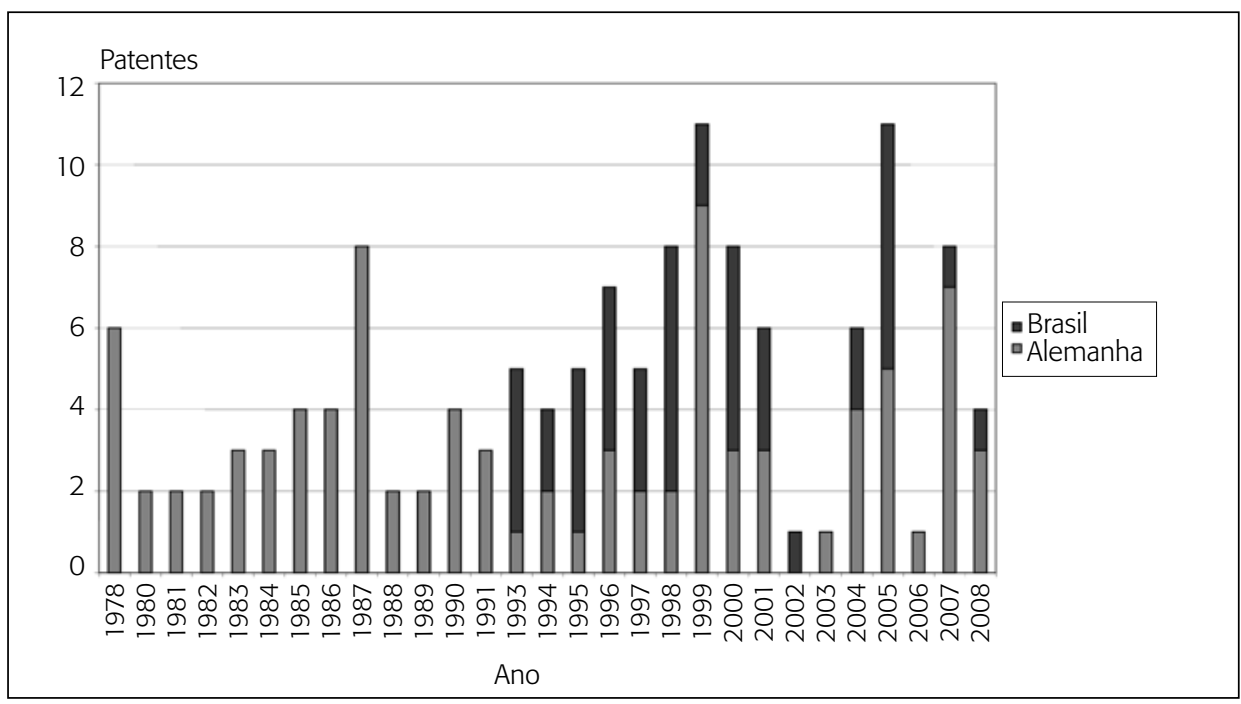

Fonte: Dados da pesquisa a partir da DWPI (2008).

Os resultados discutidos até este ponto apontam somente para o número total de patentes e sua distribuição entre a matriz e a subsidiária alemã. A tabela 1 apresenta os principais campos de aplicação para as patentes da pesquisa. Pode-se perceber uma grande concentração nos campos da engenharia e instrumentação, seguidos por química e ciência de polímeros. Esses campos estão alinhados com as competências tecnológicas do Grupo Sabó e passam a incluir especificidades da subsidiária alemã como o estudo de polímeros.

\section{Tabela 1}

Principais campos de aplicação das patentes

\begin{tabular}{|lcc|}
\hline Campo & Total & \% de 136 patentes \\
\hline Engenharia & 132 & 97,0 \\
Instrumentos e instrumentação & 129 & 94,8 \\
Química & 37 & 27,2 \\
Ciência de polímeros & 35 & 25,7 \\
\hline
\end{tabular}

Fonte: DWPI (2008) com dados da pesquisa $(n=136)$. Dados não cumulativos. 
Corroborando com os dados apresentados na figura 2 tem-se que dos quatro principais inventores três são vinculados à subsidiária alemã, com destaque para os inventores I64, I24 e I30 para a subsidiária alemã e I45 para a matriz brasileira conforme a tabela 2 .

Tabela 2

Principais inventores

\begin{tabular}{|lcc|}
\hline Código inventor & Total & \% de 136 patentes \\
\hline I64 (Alemanha) & 29 & 21,3 \\
I24 (Alemanha) & 23 & 16,9 \\
I45 (Brasil) & 16 & 11,7 \\
I30 (Alemanha) & 9 & 6,6 \\
\hline
\end{tabular}

Fonte: DWPI (2008) com dados da pesquisa $(n=65)$. Dados cumulativos.

Os grafos de redes não apresentam ligações entre patentes e inventores da matriz com a subsidiária alemã e, desse modo, ficam caracterizados os denominados buracos estruturais (structural holes), conceito ligado à ideia de capital social que se refere às conexões dentro ou entre redes sociais, como apresentadas na figura 3, onde não há ligações entre atores da matriz e subsidiária, no caso da análise do grafo, logo, não fica constatada colaboração entre esses atores. Da análise tem-se uma visão mais colaborativa na subsidiária (atores que integram a organização) e na matriz uma visão competitiva (atores que têm poder).

O foco da análise foi sobre métricas para atores, que são calculadas para cada elemento da matriz de relacionamentos, e por esse motivo também são chamadas de medidas de elemento. Da análise de redes sociais foi verificado o grau de centralidade de Freeman (1979), indicado pela figura 4 e seus atores centrais. O grau de centralidade indica o número de conexões existentes em relação ao total de conexões possíveis, ou seja, o quão bem cada indivíduo está conectado.

Para os inventores mais centrais a centralidade de saída (outdegree) foi de: I64 (26); I24 (23); I45 (17); I30 (9); I53 (7); I51 (7); I08 (5); I25 (5); 
I22 (5); I58 (5); I52 (4), o que significa que o inventor I64 contribuiu com 26 patentes e o $\mathrm{I} 24 \mathrm{com} 23$ patentes. As diferenças encontradas em relação à DWPI (tabela 2) devem-se à duplicação de nomes de inventores para a mesma patente na base original.

\section{Figura 3}

Rede de patentes e inventores para o Grupo Sabó

(1978-2008)

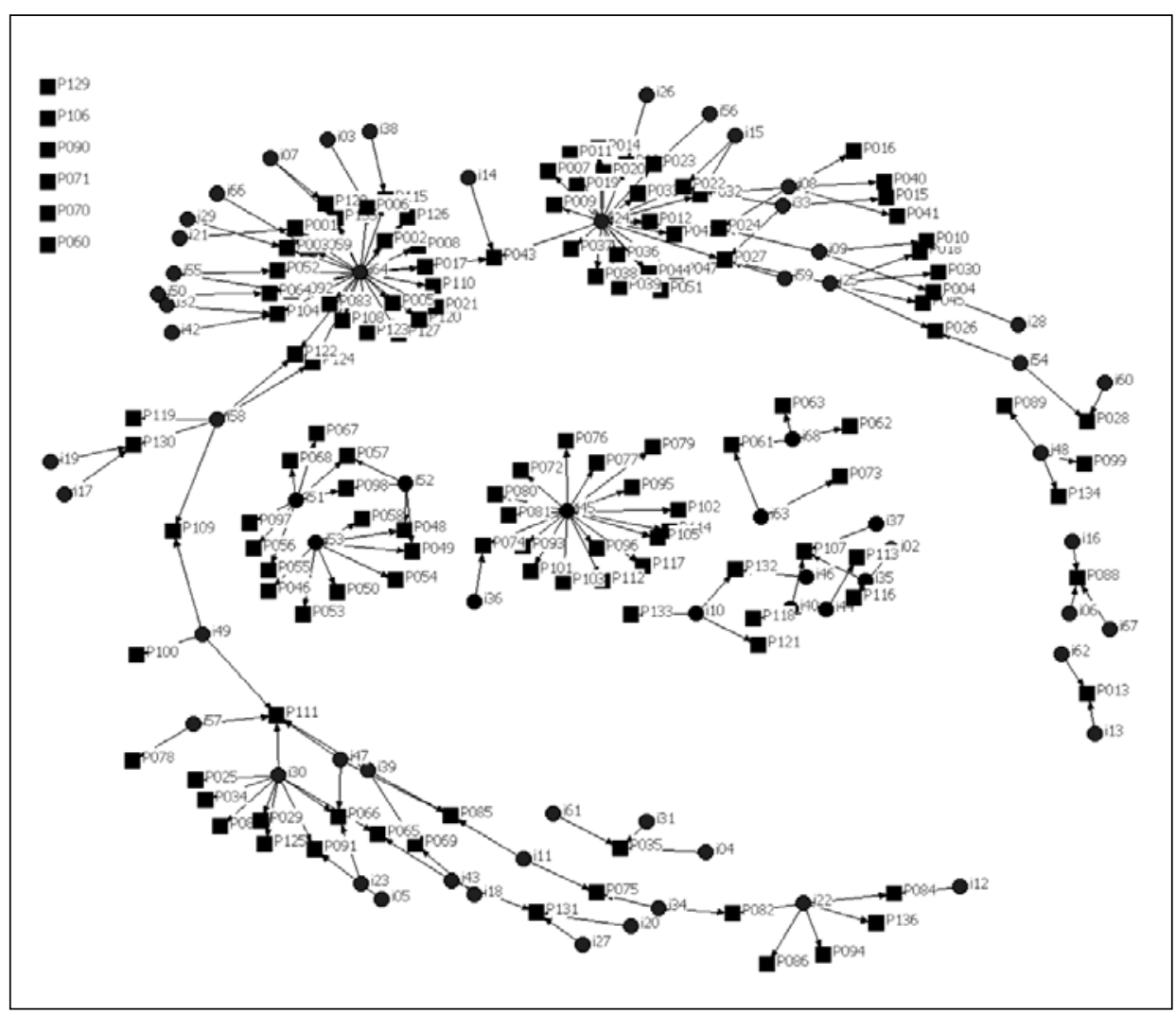

Fonte: Dados da pesquisa.

Segundo Wasserman e Faust (1994), a rede, para seus atores centrais, é do tipo estrela, em que os atores centrais ocupam uma posição de vantagem em relação aos demais, pois se outro ator, menos central, privá-lo de alguma informação ou recurso, ele pode recorrer a outras possibilidades de 
intercâmbio. Nesse tipo de rede, quanto maior for o grau de centralidade de um ator, maior será seu poder dentro da rede. A rede, quando analisadas a matriz e a subsidiária e não os atores individualmente, apresenta, no caso da matriz, uma configuração do tipo estrela fortemente apoiada em poucos atores centrais, e para a subsidiária alemã uma configuração do tipo linha abrindo-se em estrela para seus atores centrais. Pode-se notar maior colaboração na subsidiária.

\section{Figura 4}

\section{Grau de centralidade para inventores e patentes do Grupo Sabó (1978-2008)}

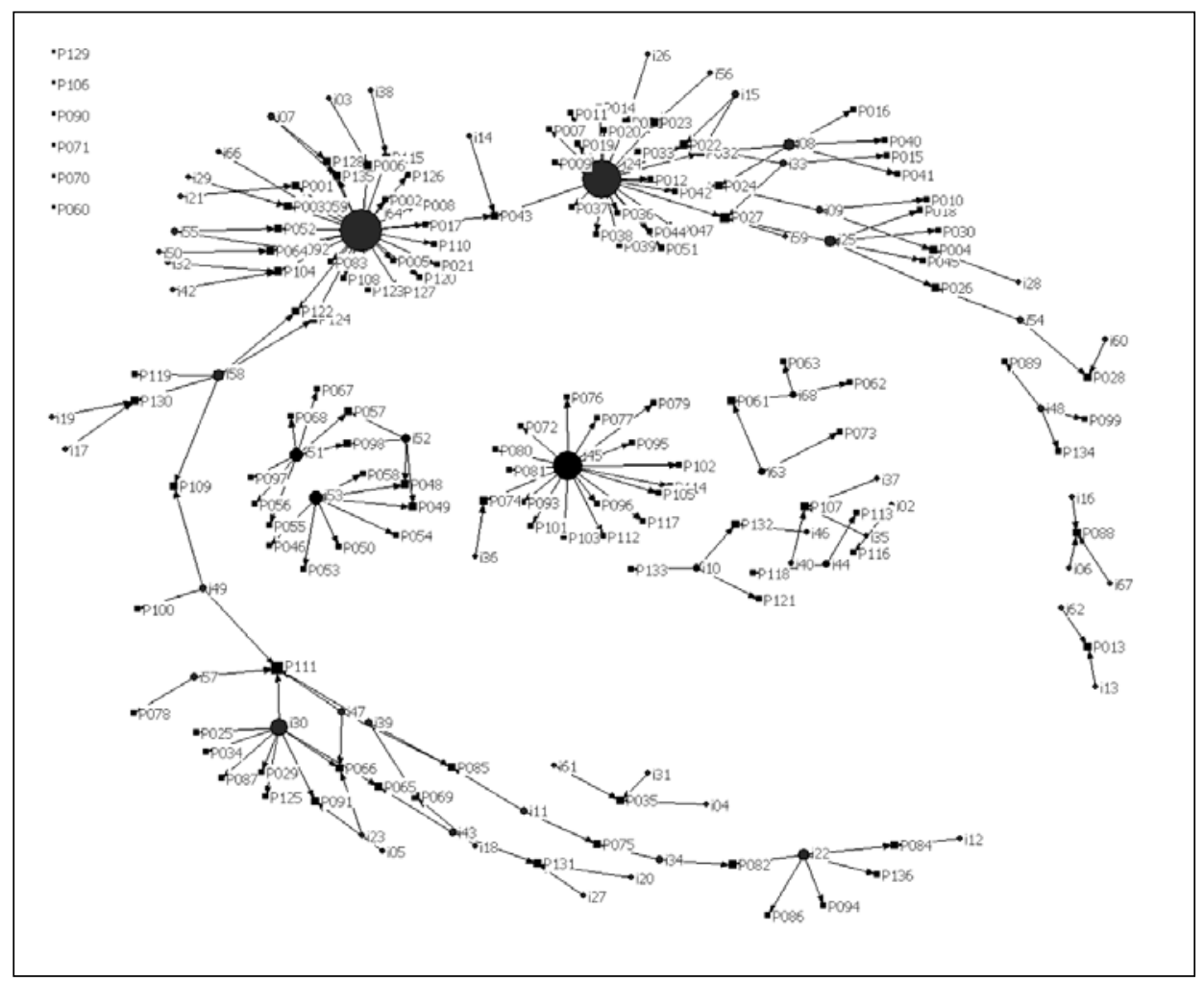

Fonte: Dados da pesquisa.

Para a medição da centralidade de intermediação (betweenness centrality), caracterizada pelos atores com posição de vantagem na rede, há um grau maior de intermediação entre os atores, ou seja, pela sua posição 
estratégica, já que eles estão no menor caminho entre dois conjuntos de atores. Assim, os outros conjuntos de atores dependem dos atores entre (between) eles. Essa medida indica qual dos atores se encontra com índice potencial para desempenhar o papel de corretagem (brokerage), de conector, de pessoa de contato (liaison) ou gatekeeping, ou seja, o número de vezes que um ator se encontra no caminho mais curto entre outros atores ajustados pelo número de alternativas de caminhos mais curtos. Segundo Cross, Parisi e Weiss (2007), conectores são atores que constantemente são procurados por outros atores para obtenção de informações, conhecimento ou mesmo para tomada de decisão. Já os brokers são pessoas que atuam como conectores entre diferentes grupos ou equipes dentro da estrutura formal de uma organização.

Como medida do grau que cada ator ocupa estruturalmente em posição vantajosa, conectando-se com outros, foi utilizada a medida de centralidade de intermediação (betweenness centrality) de Freeman (1979), que é apresentada na tabela 3 e representada visualmente na figura 5 .

Tabela 3

Centralidade de intermediação (betweenness centrality)

\begin{tabular}{|lcc|}
\hline & Betweenness & nBetweenness \\
\hline 164 & 4.945 .500 & 24.852 \\
I24 & 3.979 .400 & 19.997 \\
P043 & 3.265 .000 & 16.407 \\
I58 & 2.858 .500 & 14.364 \\
P109 & 2.464 .000 & 12.382 \\
I49 & 2.429 .000 & 12.206 \\
P111 & 2.406 .667 & 12.094 \\
I30 & 1.399 .000 & 7.030 \\
P122 & 1.377 .000 & 6.920 \\
P124 & 1.377 .000 & 6.920 \\
P027 & 1.072 .867 & 5.391 \\
I25 & 778.000 & 3.910 \\
P024 & 658.533 & 3.309 \\
\hline
\end{tabular}




\begin{tabular}{|lcc|}
\hline & Betweenness & nBetweenness \\
\hline P065 & 448.000 & 2.251 \\
Mean & 179.796 & 0.903 \\
Std Dev & 631.047 & 3.171 \\
\hline
\end{tabular}

Fonte: Dados da pesquisa com o uso do Ucinet 6.

Cabe aqui uma observação: todos os atores e patentes apresentados na tabela 3 e espelhados na figura 5 pertencem à subsidiária alemã, o que demonstra a importância estratégica da subsidiária, que pode ser determinada pelo elevado número de atores em posição de brokers na sua estrutura, o que não é observado na matriz.

Foram encontrados os outdegree para os atores mais centrais: I64 (16); I24 (13); I47 (8); I30 (8); I39 (7) e I58 (5); I49 (5); I33 (5). A centralização da rede (network centralization) tanto para outdegree como para indegree é de 10,669\%.

Figura 5

Grau de centralidade de intermediação para o Grupo Sabó (1978-2008)

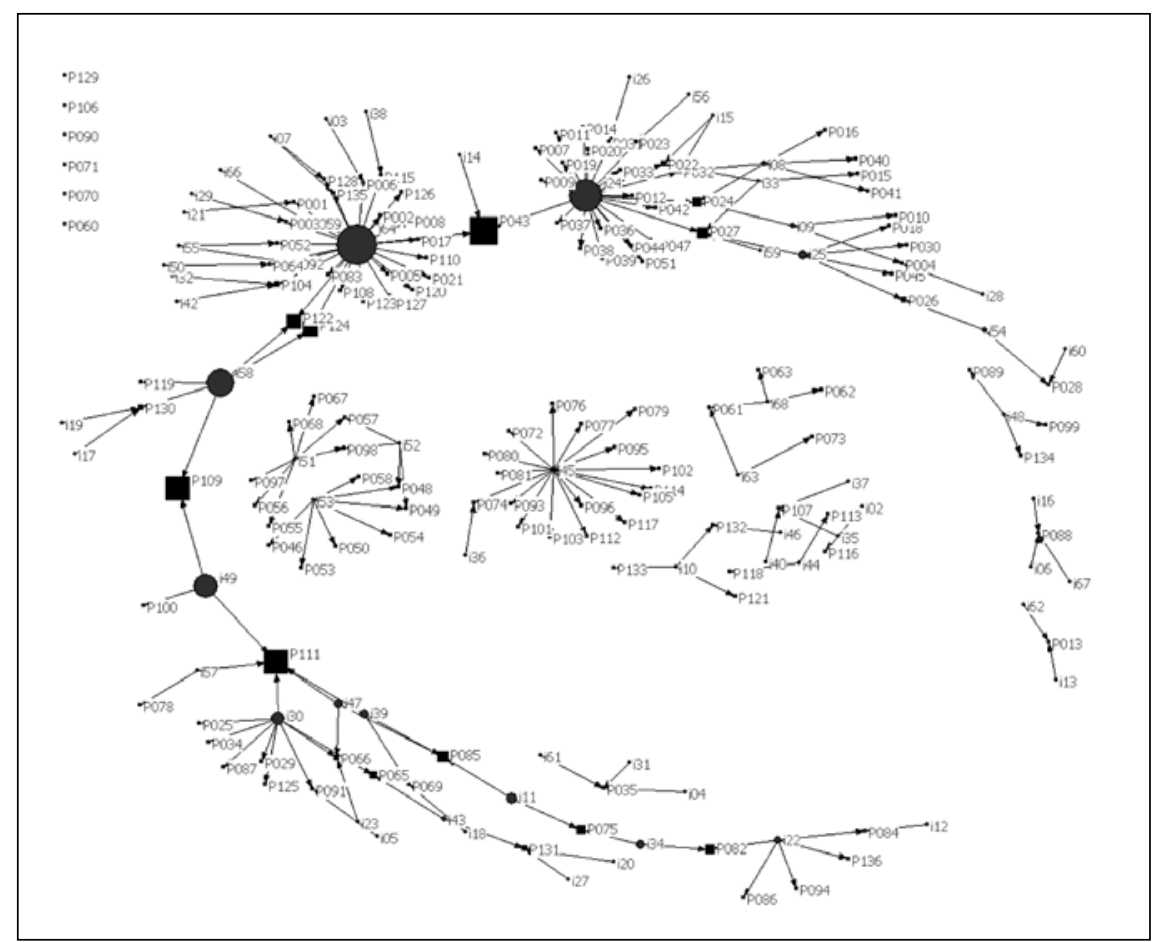

Fonte: Dados da pesquisa. 
A figura 6 apresenta o número de laços ou ligações de cada ator (inventor) destacando-se: I24 (10), I64 (13), I30 (7), I47 (6), I57 (4), I33 (4) e I25 (4). Aqui novamente fica evidenciada a importância dos atores em número de laços da subsidiária (representados pela metade à direita da figura 6) em relação à matriz representada unicamente por díades e tríades.

A figura 7, constituída pelas patentes e não pelos inventores, demonstra uma rede "mais colaborativa" (rede à esquerda na figura 7) para a subsidiária alemã em relação à matriz para as patentes do período de análise.

Figura 6

Número de laços para inventores do Grupo Sabó (1978-2008)

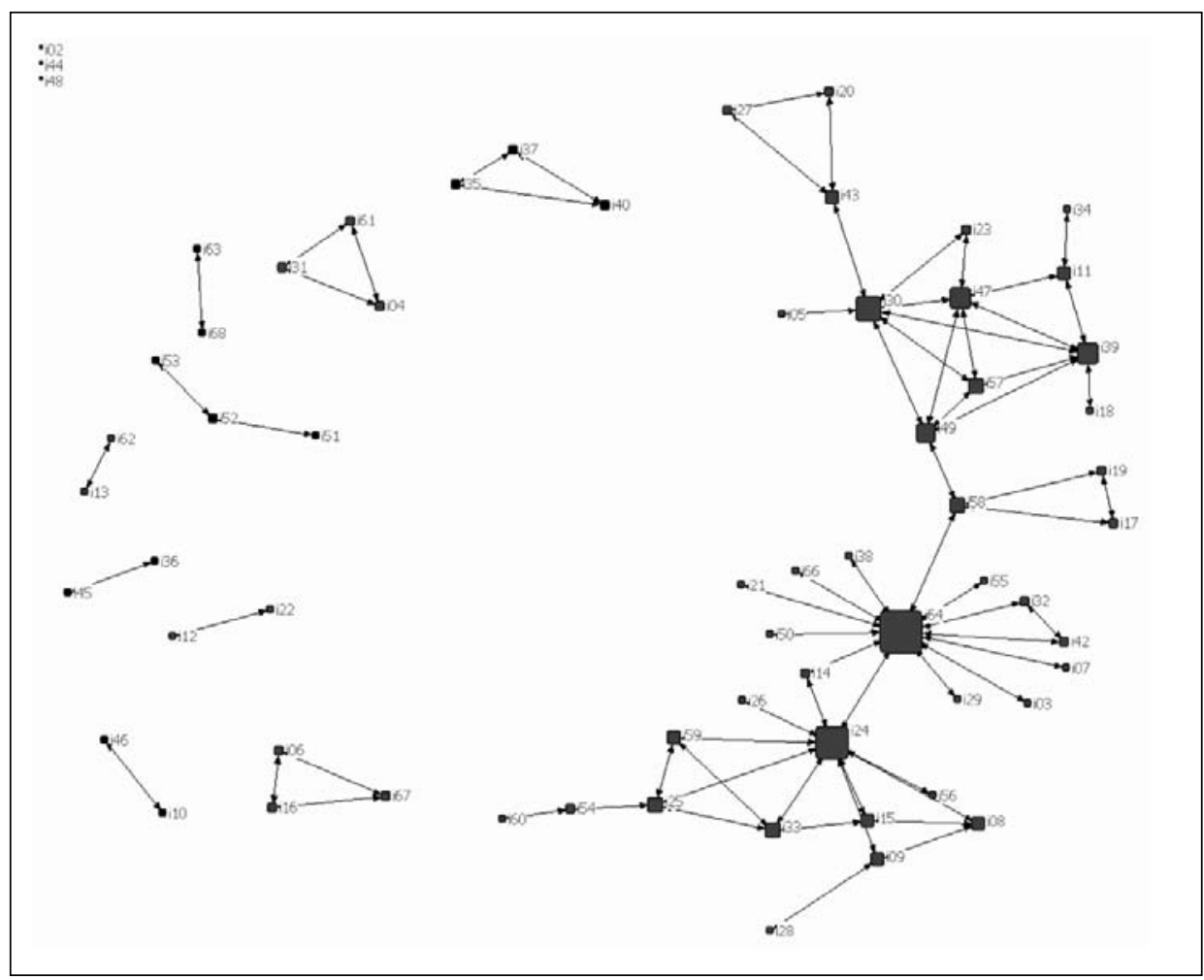

Fonte: Dados da pesquisa. 
Figura 7

Rede para patentes do Grupo Sabó (1978-2008)

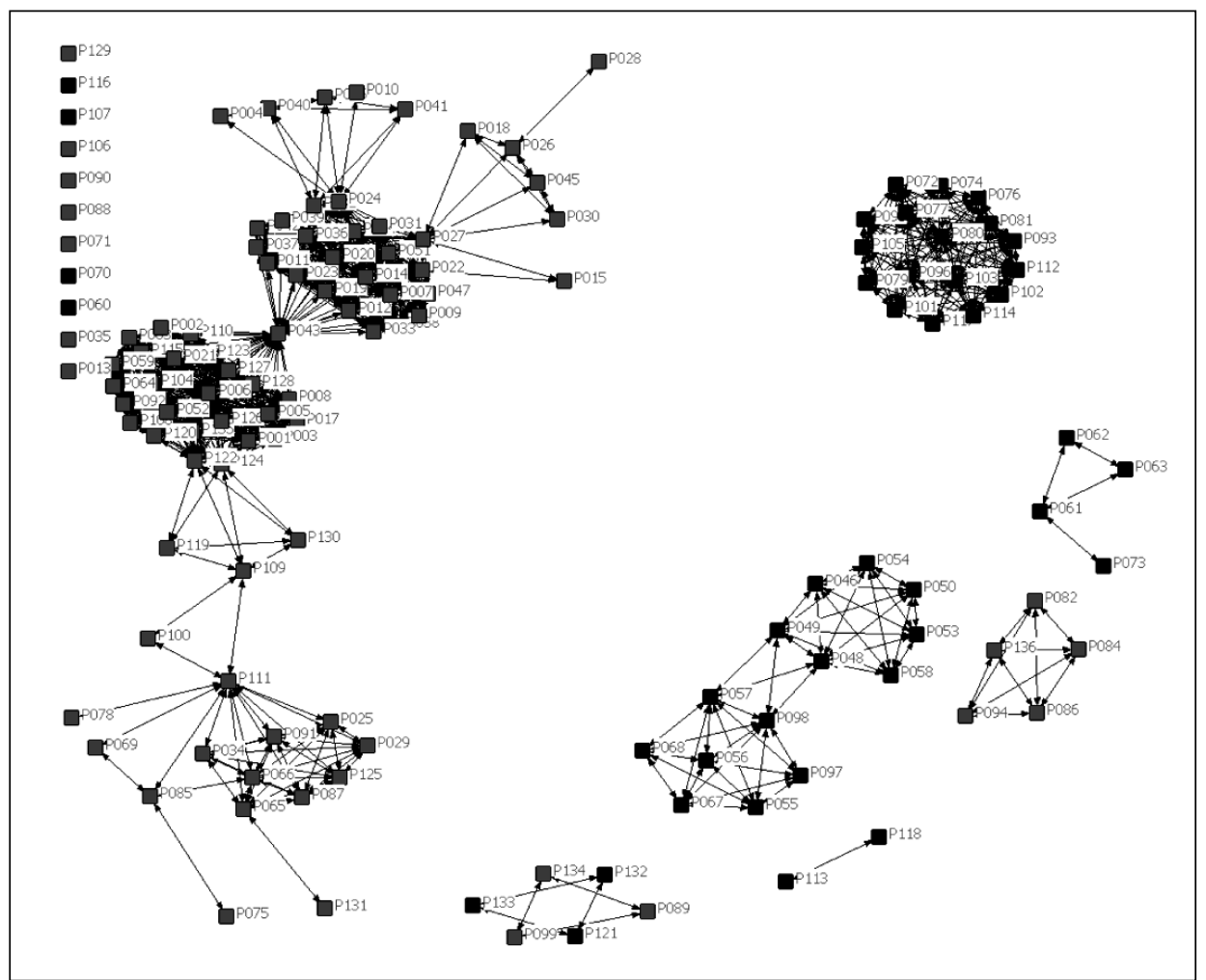

Fonte: Dados da pesquisa.

\section{Conclusão}

Uma primeira análise das competências essenciais baseada na metáfora de uma "árvore de competências" de Prahalad e Hamel (1990) apresenta, no seu sistema de raízes, a inovação e a P\&D, além do desenvolvimento de produtos básicos. Esses aspectos auxiliam a corroborar a questão da importância estratégica da subsidiária alemã, pois existe uma forte colaboração entre seus cientistas, o que pode incentivar, com novas descobertas e inovações, a equipe de desenvolvimento de produtos, o que não é objeto deste artigo. O quadro resume as competências centrais para este artigo. Cabe observar que da Alemanha parte o conhecimento em elastômeros e uma forte cultura voltada para a inovação e P\&D, raízes do desenvolvimento de competências. 


\section{Árvore de competências para o Grupo Sabó}

\begin{tabular}{|c|c|c|}
\hline \multicolumn{2}{|r|}{ Árvore } & \multirow{2}{*}{$\begin{array}{l}\text { Grupo Sabó } \\
\text { Retentores, juntas, mangueiras, selos de amortecedores, selos } \\
\text { de bombas d'água }\end{array}$} \\
\hline Frutas & Produtos finais & \\
\hline Galhos & $\begin{array}{l}\text { Unidades de } \\
\text { negócio }\end{array}$ & $\begin{array}{l}\text { Retentores, juntas e mangueiras. Divididas geograficamente: } \\
\text { Sabó (Brasil, Argentina, EUA), Kaco (Alemanha, Hungria, } \\
\text { Áustria e China) }\end{array}$ \\
\hline Tronco & Produtos básicos & Juntas, retentores e mangueiras \\
\hline Raízes & $\begin{array}{l}\text { Competências } \\
\text { organizacionais }\end{array}$ & $\begin{array}{l}\text { Cultura corporativa voltada para a internacionalização, inovação } \\
\text { e P\&D. Localização e conhecimento das necessidades dos } \\
\text { clientes }\end{array}$ \\
\hline
\end{tabular}

Fonte: Dados da pesquisa, com base em Prahalad e Hamel (1990).

Para um melhor entendimento da análise de redes sociais para o Grupo Sabó é importante destacar o processo social, desenvolvido inicialmente pela subsidiária alemã para estimular o desenvolvimento de novas patentes. Uma técnica de criatividade desenvolvida pela subsidiária alemã é baseada no Triz - theory of inventive problem solving (Altshuller, 1984). O requisito para a análise é que as invenções devem ser patenteáveis e colocadas à disposição da estratégia da companhia.

Um dos primeiros efeitos do uso do Triz é a denominada inércia psicológica, ou seja, o bloqueio da criatividade por inventores após longos anos de experiência. Os efeitos quantitativos da aplicação da técnica podem ser explicados pela elevação da média de patentes da subsidiária de três para 9,7 invenções/inovações por ano (Kaco, 2008) devido à influência do Triz.

Há três patentes-chave na subsidiária, desenvolvidas respectivamente em 1976 (inventor I64), 1982 (inventor I24) e 1996 (inventor I30), as duas primeiras ainda sem a presença da Sabó no controle e a primeira fora do período de análise da pesquisa (1978 a 2008). Os inventores relacionados nessas invenções foram admitidos na Kaco respectivamente em 1976, 1982 e 1996 e correspondem às datas das patentes-chave. Elas resultaram em: a primeira patente-chave tornou a Kaco líder de mercado em um dos seus grupos de produto; a segunda patente-chave, mais científica, auxiliou a empresa em uma melhor compreensão da função dos selos com o uso de elastômeros trazendo maior confiabilidade aos produtos; e a terceira patente-chave possibilitou a entrada de um novo e crescente segmento de produtos. Os efeitos foram quantitativos (número de patentes), qualitativos (liderança tecnológica e maior grau de inovação) e estratégicos (novos produtos, liderança e confiabilidade), além da maior produtividade dos inventores. 
Fica evidenciada a construção do capital social, na subsidiária, que se refere ao relacionamento entre atores, pois há um potencial de recursos em que atores têm à sua disposição, a partir de seus relacionamentos e investimentos pessoais. Técnicas, como o Triz, podem ser utilizadas pelos atores para sua vantagem econômica a partir da ativação de relacionamentos na sua rede social, indo de encontro a Sveiby (2001) e Sveiby, Linard e Dvorsky (2002).

A análise de redes sociais, isoladamente, não explica como foi a evolução das patentes no Grupo Sabó, mas demonstra como a rede está constituída e a força dos atores envolvidos no seu desenvolvimento. A estratégia focada em competências tecnológicas, a proximidade com seus principais clientes globais e a cultura da subsidiária demonstram que ela é um centro de excelência para o Grupo Sabó e com um papel central na questão do desenvolvimento de novas patentes, indo de encontro a Ensign e colaboradores (2000).

A análise de redes sociais indica a relevância estratégica da subsidiária alemã por meio de várias de suas métricas, ou seja, número total de patentes, total de atores envolvidos, maior centralidade desses atores, maior número de atores com centralidade de intermediação (brokers), com maior número de laços.

Uma das implicações do estudo empírico é que apresenta uma possibilidade de medição efetiva de fluxos em multinacionais utilizando a abordagem de análise de redes sociais ainda pouco difundida na literatura de negócios internacionais, para mensurar fluxos intra e interorganizacionais. Outras implicações podem ser tiradas para estudo. Primeiro, porque a ARS sugere a interação entre atores. Da análise feita observa-se uma contribuição de processos relevantes desenvolvidos pela subsidiária e sua implantação na matriz, o que pode apresentar insights gerenciais e mesmo benchmarking da conectividade em uma organização, de acordo com Cross, Parisi e Weiss (2007).

A pesquisa tem diversas limitações. Em primeiro lugar, incidiu somente sobre uma base de dados de patentes, a DWPI, podendo ser ampliada para outras bases de dados e um maior número de patentes. Segundo, porque a amostra foi definida a partir dos atores que assinam as patentes do Grupo Sabó na sua totalidade, mas não efetivamente todos aqueles que lidam com P\&D. Terceiro, o trabalho foi só com informação sobre patentes e não com as citações das mesmas e as restrições da própria estratégia de pesquisa, o estudo de caso, que não permite generalizações.

Aqui pôde ser avaliada a relação entre teoria de redes sociais e atores envolvidos com a geração de patentes em uma multinacional brasileira. Desse modo foi possível reconhecer a relevância estratégica da subsidiária alemã 
para o Grupo Sabó e como ela aperfeiçoou os mecanismos de geração de patentes e disseminou para a matriz.

\section{Referências}

ALTSHULLER, G. S. Creativity as an exact science: the theory of the solution of inventive problems. Luxemburg: Gordon \& Breach, 1984.

BARNEY, J. B.; ARIKAN, A. M. The resource-based view: origins and implications. In: HITT, M. A.; FREEMAN, R. E.; HARRISON, J. S. (Orgs.). The blackwell handbook of strategic management. Oxford: Blackwell, 2001.

BARTLETT, C. A.; GHOSHAL, S. Managing across borders: the transnational solution. Cambridge: Harvard Business School Press, 1998.

BIRKINSHAW, J. Managing internal R\&D networks in global firms: what sort of knowledge is involved? Long Range Planning, v. 35, n. 3, p. 245-267, 2002.

; FRY, N. Subsidiary initiatives to develop new markets. Sloan Management Review, v. 39, n. 3, p. 51-61, 1998.

; HOOD, N.; JONSSON, S. Building firm-specific advantages in multinational corporations: the role of subsidiary initiative. Strategic Management Journal, v. 19, n. 3, p. 221-241, 1998.

BORGATTI, S. P.; EVERETT, M. G. Network analysis of 2-mode data. Social Networks, v. 19, p. 243-269, 1997.

;

; FREEMAN, L. C. Ucinet 6 for Windows: software for social network analysis. Cambridge: Analytic Technologies, 2002.

BRESMAN, H.; BIRKINSHAW, J.; NOBEL, R. Knowledge transfer in international acquisitions. Journal of International Business Studies, v. 30, n. 3, p. 439-462, 1999.

BUCKLEY, P. J.; GHAURI, P. N. Globalization, economic geography and the strategy of multinational enterprises. Journal of International Business Studies, v. 35, n. 2, p. 81-98, 2004.

BURT, R. S. Structural holes: the social structure of competition. Cambridge: Harvard University Press, 1992.

. The contingent value of social capital. Administrative Science Quarterly, v. 42, n. 2, p. 339-366, 1997.

CAMAGNI, R.; CAPELLO, R. The role of inter-SME networking and links in innovative high-technology milieu. In: KEEBLE, D.; WILKINSON, F. (Orgs.). High-technology clusters, networking and collective learning in Europe. England: Ashgate, 2000. 
CARNEIRO, J. M. T.; CAVALCANTI, M. A. F. D.; SILVA, J. F. S. Os determinantes da sustentabilidade da vantagem competitiva na visão resource-based. In: ENANPAD, 23. Anais... Foz do Iguaçu, 1999.

CHUA, R.; MORRIS, M.; INGRAM, P. Guanxi vs networking: distinctive configurations of affect and cognition-based trust in the networks of Chinese vs American managers. Journal of International Business Studies, p. 1-19, 2008.

COLLIS, D. J.; MONTGOMERY, C. A. Competing on resources: strategy in the 1990s. Harvard Business Review, v. 37, n. 4, p. 118-128, July/Aug. 1995.

COOPER, D. R.; SCHINDLER, P. S. Métodos de pesquisa em administração. 7. ed. Porto Alegre: Bookman, 2003.

COVIELLO, N. E. The network dynamics of international new ventures. Journal of International Business Studies, v. 37, n. 5, p. 713-731, 2006.

CROSS et al. Knowing what we know: supporting knowledge creation and sharing in social networks. Organizational Dynamics, v. 30, n. 2, p. 100-120, 2001.

; PARKER, A.; NOHRIA, N. Six myths about informal networks and how to overcome them. Sloan Management Review, v. 43, n. 3, p. 67-75, Spring 2002. ; BAKER, W. What creates energy in organizations? Sloan Management Review, v. 44, p. 51-57, Summer 2003.

; PARISI, S.; WEISS, L. M. The role of networks in organizational change. The McKinsey Quarterly Web exclusive, p. 1-11, Apr. 2007.

DE PABLOS, P. O. Knowledge flow transfers in multinational corporations: knowledge properties and implications for management. Journal of Knowledge Management, v. 8, n. 6, p. 105-116, 2004.

DOZ, Y.; SANTOS, J.; WILLIAMSON, P. From global to metanational: how companies win in the knowledge economy. Boston: Harvard Business School Press, 2001.

DUNNING, J. The eclectic paradigm of international production: a restatement and some possible extensions. Journal of International Business Studies, v. 19, n. 1, p. 1-31, 1988.

. Multinational enterprises and the globalization of innovatory capacity. Research Policy, v. 23, n. 1, p. 67-88, 1994.

DWPI. Derwent World Patents Index. Disponível em: <www.thomsonreuters. com/products_services/scientific/DWPI>. Acesso em: 14 nov. 2008.

EISENHARDT, K. Building theories from case study research. The Academy of Management Review, v. 14, n. 4, 1989. 
; SANTOS F. Knowledge-based view: a new theory of strategy? In: PETTIGREW, A.; THOMAS, H.; WHITTINGTON, R. (Orgs.). Handbook of strategy and management. Sage: London, 2002.

ENSIGN, P. C.; BIRKINSHAW, J. M.; FROST, T. S. R\&D centres of excellence in Canada. In: HOLM, U.; PEDERSEN, T. (Orgs.). The emergence and impact of MNC centers of excellence - a subsidiary perspective. London: Macmillan Press, 2000.

ERIKSSON, K. et al. Experiential knowledge and cost in the internationalization process. Journal of International Business Studies, v. 28, n. 2, p. 337-360, 1997.

FEY, C. F.; BIRKINSHAW, J. External sources of knowledge, governance mode, and R\&D performance. Journal of Management, v. 31, n. 4, p. 597-621, 2005.

FOSS, N.; PEDERSEN, T. Transfering knowledge in MNCs: the role of sources of subsidiary knowledge and organizational context. Journal of International Business Studies, v. 8, n. 1, p. 49-67, 2002.

FREEMAN, Linton C. Centrality in social networks: i. conceptual clarification. Social Networks, v. 1, n. 3, p. 215-239, 1979.

FROSGREN, M.; HOLM, U.; JOHANSON, J. Managing the embedded multinational: a business network view. Cheltenham: Edward Elgar, 2005.

FROST, T. S. The geografic sources of foreign subsidiaries innovations. Strategic Management Journal, v. 22, n. 2, p. 101-123, 2001.

; BIRKINSHAW, J.; ENSIGN, P. C. Centers of excellence in multinational corporations. Strategic Management Journal, v. 23, n. 11, p. 997-1018, 2002.

FURU, P. Drivers of competence development in different types of multinational R\&D subsidiaries. Scandinavian Journal of Management, v. 17, n. 1, p. 133-149, 2001.

GRANOVETTER, M. Economic actions and social structure: the problem of embeddedness. American Journal of Sociology, v. 78, n. 3, p. 3-30, 1985.

GUPTA, A.; GOVINDARAJAN, V. Knowledge flows and the structure of control within multinational corporations. Academy of Management Review, v. 16, n. 4, p. 768-792, 1991.

. Knowledge flows within multinational corporations. Strategic Management Journal, v. 21, n. 4, p. 473-496, 2000.

HAN, Y.; BEWAJI, T.; KOTHARI, T. Social capital, manager turnover and subsidiary performance: managing double-edged social network in emerging economies. In: ACADEMY OF INTERNATIONAL BUSINESS ANNUAL MEETING, 50. Proceedings... Milan, 2008. 
HANNEMAN, R. A.; RIDDLE, M. Introduction to social network methods. Riverside: University of California, 2001.

HANSEN, M. T. The search-transfer problem: the role of weak ties in sharing knowledge across organization subunits. Administrative Science Quarterly, v. 44, n. 1 , p. 82-111, 1999.

. Knowledge networks: explaining effective knowledge sharing in multiunit companies. Organization Science, v. 13, n. 3, p. 232-248, 2002.

HARZING, A.; NOORDERHAVEN, N. Knowledge flows in MNCs: an empirical test and extension of Gupta and Govindarajan's typology of subsidiary roles. Journal of International Business Studies, v. 15, n. 3, p. 195-214, 2006.

HITT, M. A.; HOSKISSON, R. E.; KIM, H. International diversification: effects on innovation and firm performance in product-diversified firms. Academy of Management Journal, v. 40, n. 4, p. 767-798, 1997.

HO, Y.; CHIU, C. H. Brokerage-based strategy for enhancing value from the MNE's knowledge exchange network: a social network analysis. In: ACADEMY OF INTERNATIONAL BUSINESS ANNUAL MEETING, 50. Proceedings... Milan, 2008.

; ; YANG, K. S. Managing knowledge sharing in different social network relations and centrality measurements in IJVs. In: ACADEMY OF INTERNATIONAL BUSINESS ANNUAL MEETING, 50. Proceedings... Milan, 2008.

HOLM, D. B.; ERIKSSON, K.; JOHANSON, J. Business networks and cooperation in international business relationships. Journal of International Business Studies, v. 27, p. 1033-1053, 1996. Special issue.

IWASA, T.; ODAGIRI, H. Overseas R\&D, knowledge sourcing, and patenting: an empirical study of Japanese R\&D investment in the US. Research Policy, v. 33, n. 5, p. 807-828, 2004.

JENSEN, R.; SZULANSKI, G. Stickiness and the adaptation of organizational practices in cross-border knowledge transfers. Journal of International Business Studies, v. 35, n. 6, p. 508-523, 2004.

JONES, C.; HESTERLY, W. S.; BORGATTI, S. P. A general theory of network governance: exchange conditions and social mechanisms. Academy of Management Review, v. 22, n. 4, p. 911-945, 1997.

KACO. Disponível em <www.kaco.de>. Acesso em: 15 nov. 2008.

KOGUT, B.; ZANDER, U. Knowledge of the firm, combinative capabilities, and the replication of technology. Organization Science, v. 3, n. 3, p. 383-397, 1992.

KOSTOVA, T. Transnational transfer of strategic organizational practices contextual perspective. Academy of Management Review, v. 24, n. 2, p. 308-324, 1999. 
LAM, A. Organizational learning in multinationals: R\&D networks of Japanese and US MNEs in the UK. Journal of Management Studies, v. 40, n. 3, p. 673-703, 2003.

LINDQVIST, M.; SÖLVELL, Ö.; ZANDER, I. Technological advantage in the international firm, local and global perspectives on the innovation process. Management International Review, v. 40, n. 1, p. 95-126, 2000.

MADHAVAN, R.; KOKA, B. R.; PRESCOTT, J. E. Network in transition: how industry events (re)shape interfirm relationship. Strategic Management Journal, v. 19, n. 5 , p. 439-459, 1998.

MALIK, K. Coordination of technological knowledge flows in firms. Journal of Knowledge Management, v. 8, n. 2, p. 64-72, 2004.

MANOLOPOULOS, D.; PAPANASTASSIOU, M.; PEARCE, R. Technology sourcing in multinational enterprises and the roles of subsidiaries: an empirical investigation. International Business Review, v. 14, n. 3, p. 249-267, 2005.

MARKIDES, C. C.; WILLIAMSON, P. J. Corporate diversification and organizational structure: a resource-based view. Academy of Management Journal, v. 39, n. 2, p. 340-369, 1996.

MOLERO, J.; BUESA, M. Multinational companies and technological change: basic traits and taxonomy of the behaviour of German industrial companies in Spain. Research Policy, v. 22, n. 3, p. 265-278, 1992.

MONEY, R. Bruce. International multilateral negotiations and social networks. Journal of International Business Studies, v. 29, n. 4, p. 695-710, 1998.

NAHAPIET, J.; GHOSHAL, S. Social capital, intellectual capital, and the organization advantage. Academy of Management Review, v. 23, n. 2, p. 242-266, 1998.

NOBEL, R.; BIRKINSHAW, J. Innovation in multinational corporations: control and communication patterns in international R\&D operations. Strategic Management Journal, v. 19, n. 5, p. 479-496, 1998.

NOHRIA, N.; GHOSHAL, S. Differentiated network: organizing multinational corporation for value creation. San Francisco: Jossey-Bass, 1997.

OLIVER, A. L.; EBERS, M. Networking network studies: an analysis of conceptual configurations in the study of inter-organizational relationships. Organization Studies, v. 19, n. 4, p. 549-583, 1998.

PANTZALIS, C. Does location matter? An empirical analysis of geographic scope and MNC market valuation. Journal of International Business Studies, v. 32, n. 1, p. 133-155, 2001. 
POLYANI, K. The great transformation. Boston: Beacon Press, 1957.

POWELL, W. W. Neither market nor hierarchy: network forms of organization. Research in Organizational Behavior, v. 12, p. 295-336, 1990.

PRAHALAD, C. K.; HAMEL, G. The core competence of the corporation. Harvard Business Review, v. 68, n. 3, p. 79-91, 1990.

RAINER, H.; MEIERKORD, T. "Don't rest on your laurels": an inquiry into barriers to radical follow-up innovation in new technology based ventures. International Journal of Technology Intelligence and Planning, v. 4, n. 1, p. 39-54, 2008.

RUGMAN, A. M. Inside the multinationals: the economics of internal markets. New York: Columbia University Press, 1981.

; VERBEKE, A. Subsidiary-specific advantages in multinational enterprises. Strategic Management Journal, v. 22, n. 3, p. 237-250, 2001.

SADOWSKI, B. M.; DITTRICH, K.; DUYSTERS, G. M. Collaborative strategies in the event of technological discontinuities: the case of Nokia in the mobile telecommunication industry. Small Business Economics, v. 21, n. 2, p. 173-186, 2003.

STABELL, C. B.; FJELDSTAD, Q. D. Configuring value for competitive advantage: on chains, shops, and networks. Strategic Management Journal, v. 19, n. 5, p. 413437, 1998.

STAKE, R. Case studies. In: DENZIN, N.; LINCOLN, T. Handbook of Qualitative Research. London: Sage, 2005.

SVEIBY, K. E. A knowledge-based theory of the firm to guide in strategy formulation. Journal of Intellectual Capital, v. 2, n, 4, p. 344-358, 2001.

; LINARD, K.; DVORSKY, L. Building a knowledge based strategy: a system dynamics model for allocating value added capacity. In: INTERNATIONAL CONFERENCE OF THE SYSTEM DYNAMICS SOCIETY, 20. Proceedings... Palermo, Itália, 2002.

TASI, W. Knowledge transfer in intraorganizational networks: effects of network position and absorptive capacity on business unit innovation and performance. Academy of Management Journal, v. 44, n. 5, p. 996-1004, 2001.

WASSERMAN, S.; FAUST, K. Social network analysis: methods and applications. Cambridge: Cambridge University Press, 1994.

YIN, R. Case study research: design and methods. London: Sage, 1986. 